УДК 582(571.63)

dx.doi.org/10.24866/7444-4911-7/12-15

\title{
Формирование ритидома у дуба монгольского (QuercusmongolicaFisch. ex Ledeb.,FabaceaeLindl.)
}

\section{А.С. Коляда}

В работе освещается формирование ритидома у одного из самых распространённых древесных растений Дальнего Востока России - дуба монгольского

Ключевые слова: дуб монгольский, ритидом, Дальний Восток России

Ритидом (корка) - третичная покровная ткань, образующаяся у древесных растений и сменяющая вторичную покровную ткань ствола, перидерму.

В зимний период 2019-2020 гг. автором изучались особенности формирования перидермы у одного из наиболее распространённых видов древесных растений Приморского края - дуба монгольского (QuercusmongolicaFisch. exLedeb.) из семейства Буковые (FabaceaeLindl.). Типичный представитель Маньчжурской флоры, он участвует в формировании смешанных лесов различного типа (Добрынин, 2000).

По структуре третичной покровной ткани Quercusmongolica относится к видам с бороздчатым ритидомом (Коляда, 2002).

В процессе исследования использовались визуальные наблюдения трансформации покровной ткани ветвей и ствола. Поперечные срезы готовились вручную опасной бритвой и рассматривались с помощью микроскопов МБС-9 и Микмед-1.

Перидерма первого года коричневая, гладкая. Заметна белёсая растрескивающаяся эпидерма (рис. 1), более выраженная в узлах. Чечевички линзовидные, светло-кремовые (контрастирующие с окраской стебля), около 0,6 мм длины и 0,3 мм ширины,с центральным продольным растрескиванием. Число слоёв клеток пробки 8-11.

Перидерма второго года становится серой (либо серо-коричневой), эпидерма отходит лохмотьями (рис. 1). Чечевички становятся округлыми, выпуклыми.

Более старая перидерма (диаметр ствола до 2-3 см) серо-коричневая, с разбросанными небольшими тёмными пятнами, блестящая, голая. Чечевички мелкие, продольно ориентированные, окружающие чечевичку ткани формируют небольшой (до 3 мм) горизонтальный валик.

По тёмным пятнам нередко заметны многочисленные чёрные точки или штрихи. Иногда чечевички окружены участком тканей, более тёмными по сравнению с остальной серой частью ствола.

Перидерма пятого года серо-блестящая, гладкая, голая. Чечевички становятся поперечными. Эпидерма к этому времени может полностью сходить, но некоторых случаях она сохраняется и на шестилетних стеблях (рис. 2). Наблюдается её растрескивание, главным образом по чечевичкам. Число слоёв клеток пробки в перидерме варьирует от 18 до 21.

После достижения диаметра ствола в 4-6 см начинается продольное растрескивание (рис. 3). Чаще оно начинается в местах расположения чечевичек.

Растрескивание свидетельствует о начале формирования ритидома. На поперечном срезе в месте растрескивания (рис. 3) заметны образовавшиеся дополнительные слои перидермы. 

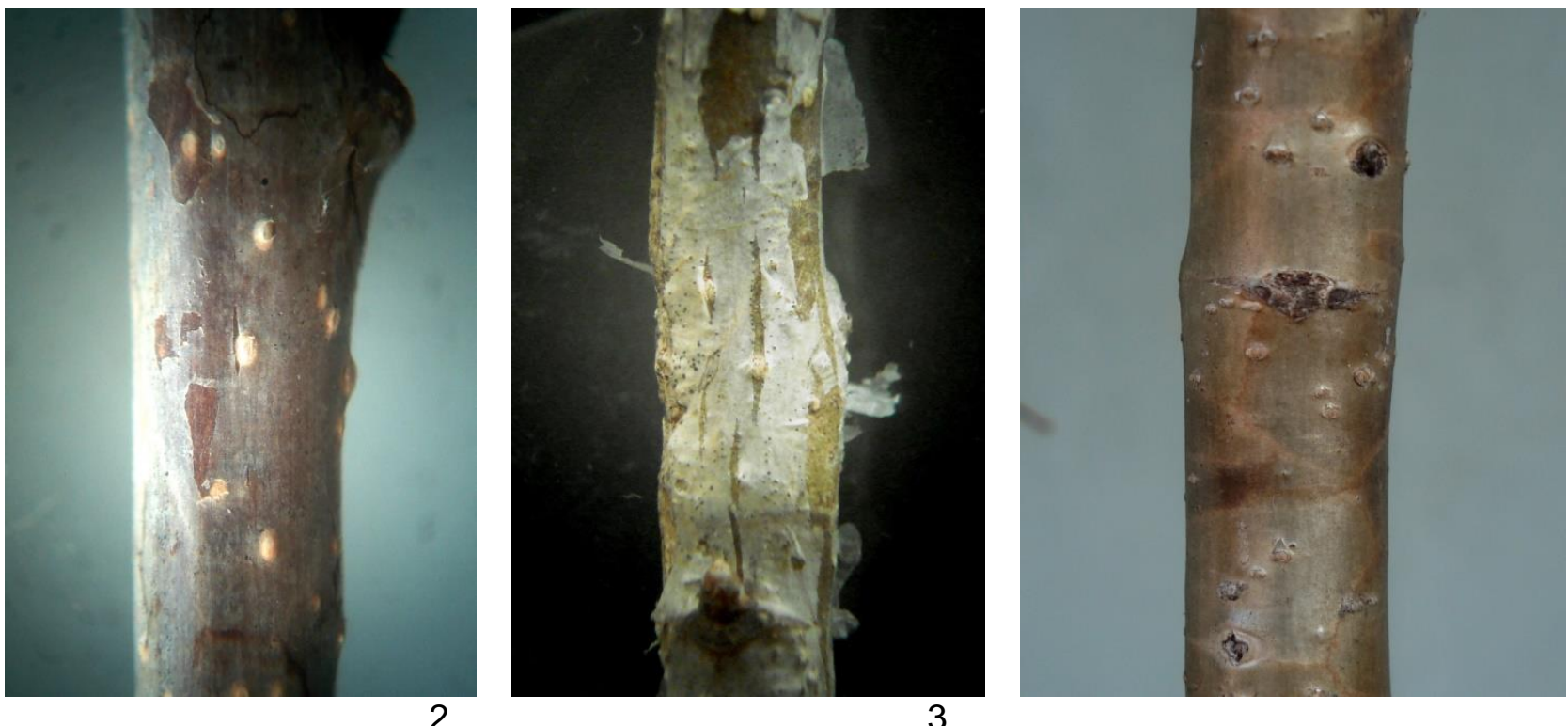

Рис. 1. Однолетний (1), двулетний (2) и трёхлетний (3) стебли дуба монгольского
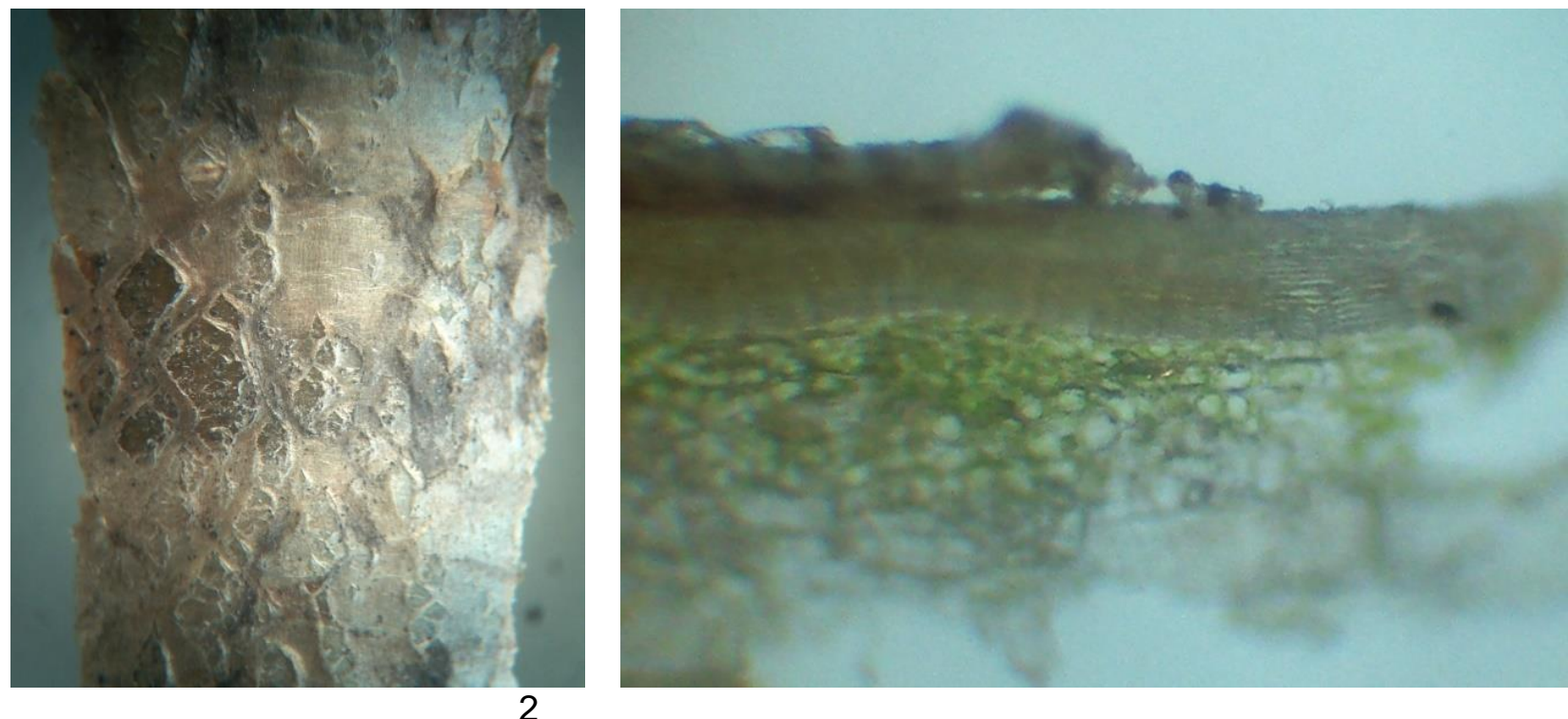

Рис. 2. Шестилетний стебель дуба монгольского(1) и поперечный срез наружных тканей (2)
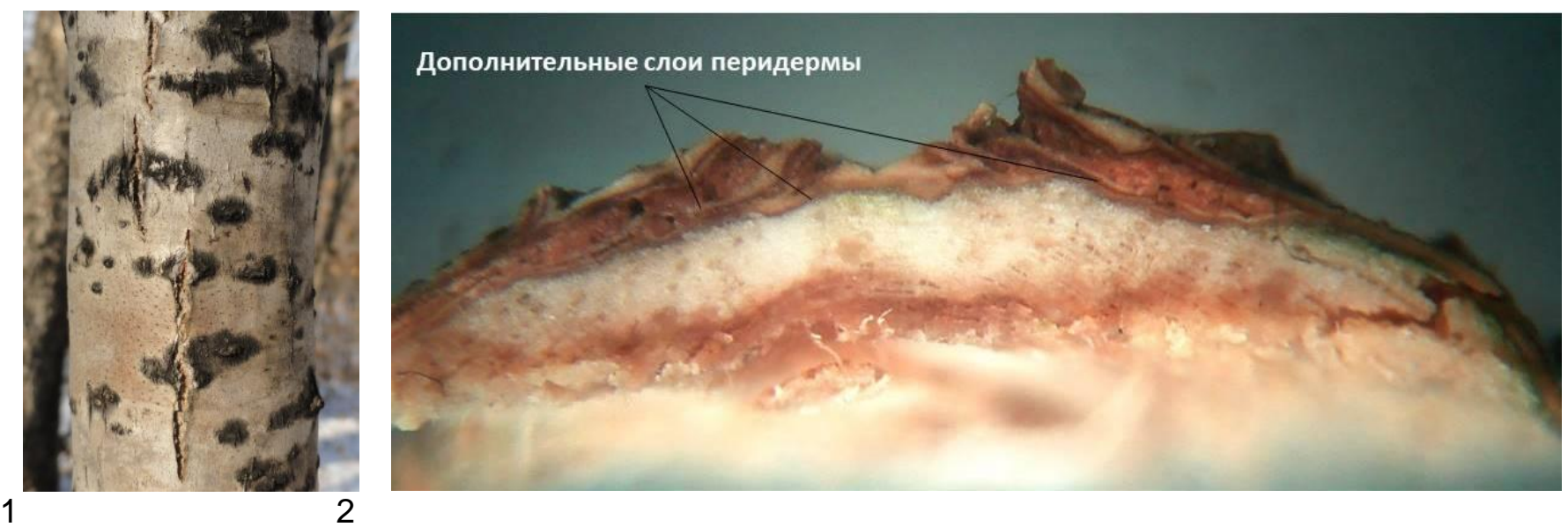

Рис. 3. Начало растрескивания покровных тканей ствола дуба монгольского (1); образование дополнительных слоёв перидермы (2) 
Ритидом ствола пёстрый (серый с более тёмными, реже светлыми пятнами). Основание трещин коричневое, светло-коричневое или серое. Размер чечевичек может достигать 0,5-0,7 см, при этом валик не формируется.

С увеличением диаметра ствола растрескивание становится все более интенсивным увеличивается глубина и ширина трещин (рис. 4). Площадь визуально ровных участков (с одним слоем перидермы) постоянно уменьшается.

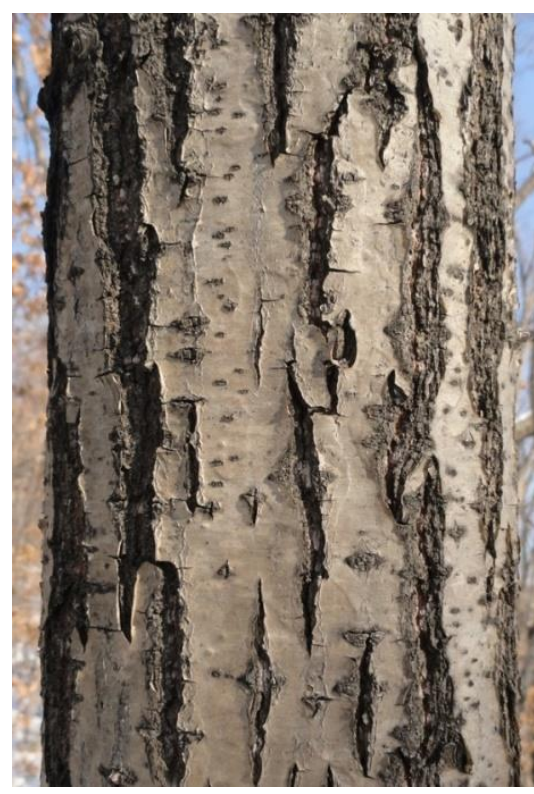

2

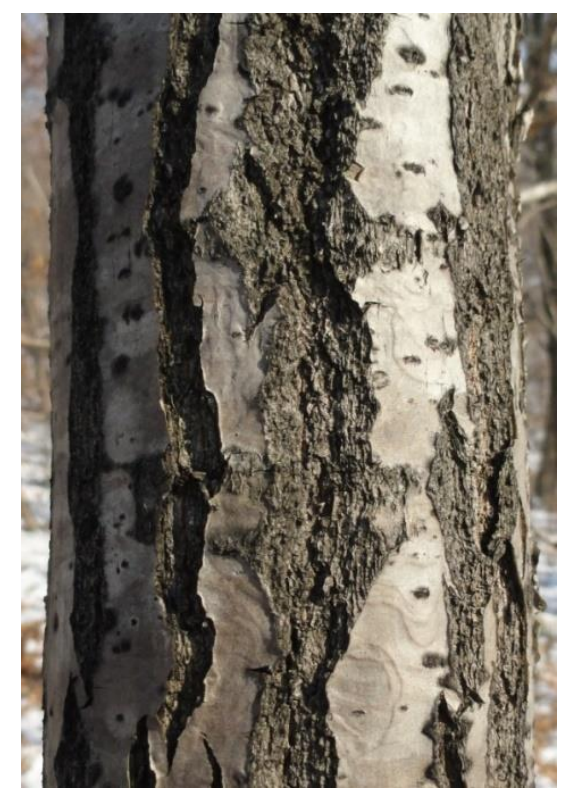

3

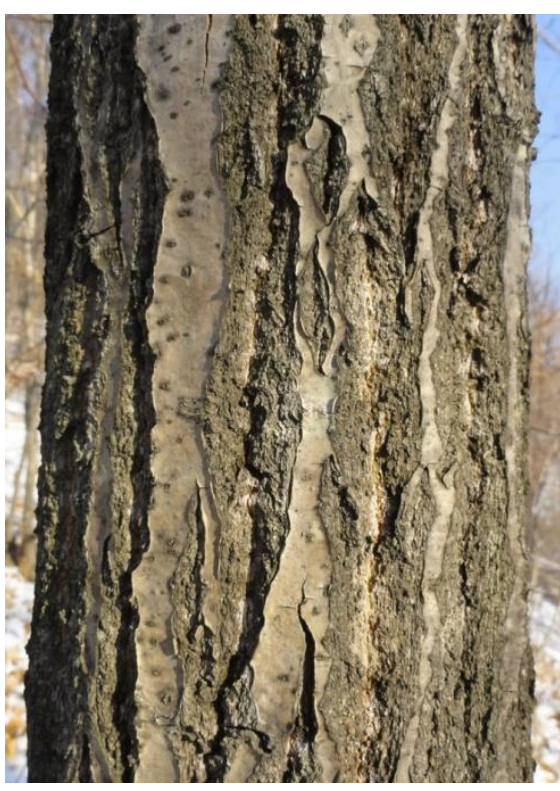

Рис. 4. Формирование ритидома дуба монгольского

Ритидом зрелого дерева (рис. 4) тёмно-серый, выраженно бороздчатый. Отслаивание верхних слоев борозд слабое. С возрастом на верхушках гребней появляются и поперечные трещины. Нередко наличие лишайников. На поперечном срезе (рис. 5) заметны несколько (5-7) слоёв перидермы.
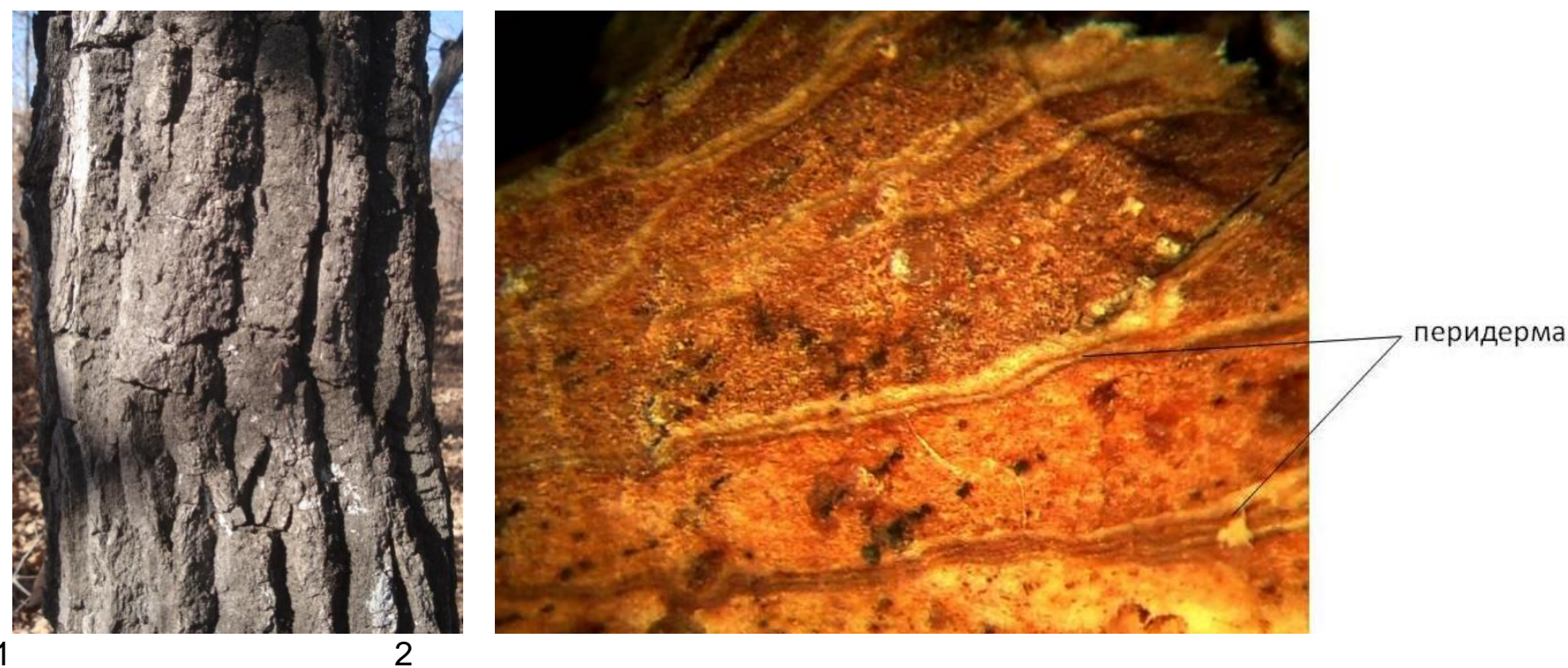

Рис. 5. Ритидом зрелого дерева дуба монгольского (1) и его структура (2) 


\section{Литература}

Добрынин А.П. Дубовые леса российского Дальнего Востока (биология, география, происхождение) // Труды ботанических садов Дальневосточного отделения РАН. Владивосток, 2000. Т. 3.

Коляда А.С. Особенности структуры покровных тканей стволов древесных растений Приморского края // Животный и растительный мир Дальнего Востока Вып. 6. Серия: Экология и систематика растений. Уссурийск: Изд-во УГПИ, 2002. С. 16-20.

\section{Rhytidome formation in Mongolian oak (QuercusmongolicaFisch. exLedeb.,FabaceaeLindl.)}

\footnotetext{
A.S. Kolyada

Rhytidome formation in one of the most common arboreal plants of the Russian Far East Mongolian oak - isdiscussedin the paper.

Keywords: Mongolian oak, rhytidome, Russian Far East.

\section{Сведения об авторах:}

Коляда Александр Степанович - доцент кафедры естественнонаучного образования Дальневосточного федерального университета, филиала в г. Уссурийске (Школы педагогики), к.б.н., доцент; 692500, Приморский край, г. Уссурийск, ул. Некрасова, 35; e-mail: a.s.pinus@mail.ru.
} 